\title{
Planning Water Resources Systems under Uncertainty Using an Interval-Fuzzy De Novo Programming Method
}

\author{
D. Y. Miao ${ }^{1,2}$, W. W. Huang ${ }^{3}$, Y. P. Li ${ }^{1, *}$, and Z. F. Yang ${ }^{2}$ \\ ${ }^{1}$ MOE Key Laboratory of Regional Energy Systems Optimization, Resources and Environmental Research Academy, North China Electric Power \\ University, Beijing 102206, China \\ ${ }^{2}$ School of Environment, Beijing Normal University, Beijing 100875, China \\ ${ }^{3}$ Department of Civil Engineering, McMaster University, Hamilton, Ontario L8S 4L7, Canada
}

Received 18 July 2012; revised 19 September 2013; accepted 15 October 2013; published online 19 September 2014

\begin{abstract}
This study presents an interval-fuzzy De Novo programming (IFDNP) method for planning water-resourcesmanagement systems under uncertainty. IFDNP is derived by incorporating the concepts of interval parameters and fuzzy sets within a De Novo programming framework. IFDNP has the advantages in constructing optimal system design through introducing the flexibility into the available resources in the model's constraints. Moreover, IFDNP allows the decision makers to achieve a metaoptimal system performance and improve the performance of compromise solutions, and it is effective for dealing with the system design problems involving multiple objectives and multiple uncertainties. The IFDNP is then applied to a case study of designing an inexact optimal system with budget limit for water resources management and planning. Various scenarios that are associated with different levels of economic implication consequences and water allocation patterns under uncertainty are analyzed. Results can help decision makers to evaluate alternatives of system designs and to determine which of these designs can most efficiently achieve the desired economic objective constrained by limited resources.
\end{abstract}

Keywords: De Novo programming, fuzzy sets, interval analysis, multiobjective, planning, water resources systems

\section{Introduction}

In recent decades, the constantly increasing demand for water in terms of both sufficient quantity and satisfied quality has forced planners to contemplate and propose ever more comprehensive, complex and ambitious plans for water resources systems ( $\mathrm{Li}$ et al., 2008a). However, such planning efforts are complicated with a variety of uncertain parameters as well as their interactions. Moreover, these uncertainties may be amplified by limited budget and limited resources with a maximized system benefit objective. It is an active process that seeks a portfolio of resource levels and optimizes the objecttive function by allocating a budget according to a resource price, where resource levels are considered as decision variables (Zeleny, 1990). Therefore, it is necessary to develop effective optimization methods for supporting water resources management under such complexities and uncertainties (Zhang et al., 2009).

Previously, a number of methods such as fuzzy, stochastic and interval mathematical programming were developed for dealing with the uncertainties in water resources

* Corresponding author. Tel.: +8610 61773887; fax: +86 1061773885 .

E-mail address: yongping.li@iseis.org (Y. P. Li).

ISSN: 1726-2135 print/1684-8799 online

(C) 2014 ISEIS All rights reserved. doi:10.3808/jei.201400277 management problems (Slowinski, 1986, 1987; Kindler, 1992; Chang et al., 1996; Russell and Campbell, 1996; Wu et al., 1997; Ferrero et al., 1998; Teegavarapu and Simonovic, 1999; Jairaj and Vedula, 2000; Seifi and Hipel, 2001; Lee and Chang, 2005; Maqsood et al., 2005; Li et al., 2008b, 2009, 2011; Barbalios et al., 2013; Su et al., 2013; Xu and Qin, 2013). For example, Slowinski (1986) proposed an interactive fuzzy multiobjective linear programmming method for planning water resources supply systems. Huang (1996) employed interval-parameter programming (IPP) method for water quality management within an agricultural system, where uncertainties expressed as discrete intervals were effectively adderssed. Wu et al. (1997) proposed an interactive inexact-fuzzy multi-objective programming model for planning water resources systems, where IPP and fuzzy programming (FP) were incurporated within a multiobjective framework to handle uncertainties presented in terms of discrete intervals and fuzzy sets. Jairaj and Vedula (2000) optimized a multi-reservoir system using fuzzy mathematical programming method, where the uncertainties existing in reservoir inflows were treated as fuzzy sets. Bender and Simonovic (2000) proposed a fuzzy compromise approach for water resources planning under imprecision uncertainty. Lee and Chang (2005) proposed an interactive fuzzy approach for planning a stream water resources management system that involved vague and imprecise information. Li et al. (2009) advanced a multistage fuzzy-stochastic programming model for water-resources allo- 
cation and management, where uncertainties expressed as probability distributions and fuzzy sets could be reflected.

Generally, FP was effective in dealing with decision problems under fuzzy goal and constraints and handling ambiguous coefficients in the objective function and constraints (Dubois and Prade, 1978; Zimmermann, 1995); IPP could handle uncertain parameters that were expressed as intervals with known lower and upper bounds, but unknown membership or distribution functions (Huang, 1996). The conventional planning problems using fuzzy interval, and/or stochastic program mostly focused on optimizing a given system subject to a series of constraint resources which were fixed as a number of deterministic values. However, in real-world practical problems, the constraint resources possess imprecise features, which are difficult to be determined precisely. Compared with the traditional inexact optimization methods, De Novo programming approach can effectively handle the optimal system design problems with the available resources. These resources are considered as decision variables in De Novo program subject to the budgetary constraints, which can thus affect the objective function values. In De Novo programming problems, uncertainties may exist in the related costs, system objectives, and modeling parameters; uncertain parameters can be represented as fuzzy, interval or stochastic numbers, resulting in inexact De Novo programming (Zhang et al., 2009).

De Novo programming, which was effective for dealing with optimal design problems with unknown resource availability and seeking a portfolio of resource availability level to optimize multiple objective functions by allocating a budget according to the resource price, was an attractive technique in response to the above challenges (Zeleny, 1981, 1986, 1990). Previously, a number of research works based on the De Novo programming were applied to various system design cases (Bare and Mendoza, 1988, 1990; Li and Lee, 1990, 1993; Kim et al., 1993; Sasaki et al., 1995; Shi, 1995; Kotula, 1997; Zeleny, 2005; Chen and Hsieh, 2006; Zhang et al., 2009). For example, Bare and Mendoza (1988) employed De Novo programming to single and multi-objective forestry land management problems, where a number of constraints such as labor, picnic sites, and hiking trails were considered; the study system could be designed to perform in an ideal fashion within a constant budget level. Zeleny (1990) proposed a basic method to construct the optimal system design for solving a De Novo problem via an ideal system design; one of the important issues in multicriteria De Novo programming was to determine an optimum-path ratio for enforcing a particular budget level of resources so as to establish the optimal system design. Li and Lee (1990) extended Zeleny's basic method to identify fuzzy system designs for De Novo problems by considering the fuzziness in coefficients, and further treated fuzzy goals and fuzzy coefficients simultaneously, depending on a numerical approach which could be solved as either linear or nonlinear problems (Li and Lee, 1993). Kim et al. (1993) formulated a De Novo 0-1 bicriteria linear programming with interval coefficients under generalized upper bounding structure, where interval coefficients were trans- formed into a fuzzy state by the fuzzy transformation based on the degree of satisfying inequality relationship and order relationship between intervals; however, the main limitation of this transformation method was to generate a generalized De Novo model. Sasaki et al. (1995) proposed an implementtation of the genetic algorithm for solving De Novo programming problems with fuzzy goal and constraints, which possessed the flexibility to obtain better solutions compared to crisp constraints. Shi (1995) introduced several optimum-path ratios for enforcing different budget levels of resources to identify alternative optimal system designs for solving multicriteria De Novo programming problems. Kotula (1997) used the De Novo programming for control and adjustment of reservoir design and operation characteristics which resulted in optimal or near optimal system performance throughout the life of the reservoir. Zeleny (2005) investigated the evolution of optimality of single and multiobjective programming, where a number of major optimality concepts according to a dual classification were discussed. Chen and Hsieh (2006) presented a fuzzy multistage De Novo programming, where random distribution of budget was analyzed. More recently, Zhang et al. (2009) developed an interval De Novo programming (IDNP) method through introducing IPP technique into the De Novo programming framework for the planning of water-resources systems, where uncertainties presented as discrete intervals were addressed; however, the IDNP was incapable of handling problems containing vague information. In fact, in many real-world problems, results produced by optimization techniques could be rendered highly questionable if the modeling inputs could not be expressed with precision (Li et al., 2009; Fan and Huang, 2012; Suo et al., 2013). Quality of the available information was generally poor, and uncertainties might be presented as fuzzy sets, interval values, and their combinations.

Therefore, one approach to potentially address these uncertainties is to integrate both fuzzy programming (FP) and interval-parameter programming (IPP) into the De Novo programmming framework; this will lead to an interval-fuzzy De Novo programming (IFDNP) method. The developed IFDNP can effectively deal with uncertainties expressed as fuzzy sets and interval values in single and multiobjective problems. The IFDNP will then be applied to a case study of water resources systems planning, which designs an inexact optimal system with budget limit and different weights. A number of scenarios will be examined to identify an optimum system design under multiple objectives and multiple uncertainties. The results obtained can help decision makers to evaluate alternatives of system designs and to determine which of these designs can most efficiently achieve the desired economic objective constrained by limited resources.

\section{Methodology}

\subsection{Interval Fuzzy Linear Programming}

An interval fuzzy linear programming (IFLP) problem can be formulated as follows (Huang et al., 1993): 
$\max f^{ \pm} \equiv C^{ \pm} X^{ \pm}$

Subject to:

$A^{ \pm} X^{ \pm} \leq B^{ \pm}$

$X^{ \pm} \geq 0$

where $A^{ \pm} \in\left\{R^{ \pm}\right\}^{m \times n}, B^{ \pm} \in\left\{R^{ \pm}\right\}^{m \times 1}, C^{ \pm} \in\left\{R^{ \pm}\right\}^{1 \times n}, X^{ \pm} \in\left\{R^{ \pm}\right\}^{n \times 1}$ and $\left\{R^{ \pm}\right\}$denote a set of intervals; symbols $\bar{\approx}$ and $\leqq$ represent fuzzy equality and inequality. In fact, a decision in a fuzzy environment can be defined as the intersection of membership functions corresponding to fuzzy objective and constraints (Chang et al., 1997). Given a fuzzy goal $(G)$ and a fuzzy constraint $(E)$ in a space of decision alternatives $\left(X^{ \pm}\right)$, a fuzzy decision set $(D)$ can then be formed in the intersection of $G$ and $E$. In a symbolic form, we have $D=G \cap E$, and correspondingly:

$\mu_{D}=\min \left\{\mu_{G}, \mu_{E}\right\}$

where $\mu_{D}, \mu_{G}$ and $\mu_{E}$ denote membership functions of fuzzy decision $D$, fuzzy goal $G$, and fuzzy constraint $E$, respectively (Zimmermann, 1995; Li et al., 2008a). Let $\mu_{E_{i}}\left(X^{ \pm}\right)$be membership functions of constraints $E_{i}(i=1,2, \ldots, m)$, and $\mu_{G_{j}}\left(X^{ \pm}\right)$be those of goals $G_{j}(j=1,2, \ldots, n)$. A decision can then be defined by the following membership function (Huang et al., 2001; Li et al., 2008a):

$\mu_{D}\left(X^{ \pm}\right)=\mu_{E_{i}}\left(X^{ \pm}\right) * \mu_{G_{j}}\left(X^{ \pm}\right)$

$\mu_{D}\left(X^{ \pm}\right)=\min \left\{\mu_{i}\left(X^{ \pm}\right) \mid i=1,2, \ldots, m+1\right\}$

where $X^{ \pm}$represents a set of decision variables; “*” denotes an appropriate and possibly context-dependent "aggregator"; $\mu_{i}\left(X^{ \pm}\right)$can be interpreted as the degree to which $X^{ \pm}$satisfies fuzzy inequality in the objective and constraints. A desired decision is thus the one with the highest $\mu_{D}\left(X^{ \pm}\right)$value:

$\max \mu_{D}\left(X^{ \pm}\right)=\max \min \left[\mu_{i}\left(X^{ \pm}\right)\right], X^{ \pm} \geq 0$

where $\mu_{i}\left(X^{ \pm}\right)$should be zero if the objective and constraints are violated, and 1 if they are totally satisfied. Consequently, the IFLP problem can be converted into an ordinary linear programming model by introducing a control variable of $\lambda=\mu_{D}\left(X^{ \pm}\right)$, which corresponds to the membership function of the fuzzy decision (Zimmermann, 1995; Chang et al., 1997; Huang et al., 2001; Li et al., 2008a). Specifically, the flexibility in the constraints and fuzziness in the objective (which are represented by fuzzy sets and denoted as "fuzzy constraints" and "fuzzy goal", respectively), can be expressed as membership grades $(\lambda)$ corresponding to the degrees of overall satisfaction for the constraints and objective. Thus, model (1) can be converted into:

$\max \lambda^{ \pm}$

Subject to:

$C^{ \pm} X^{ \pm} \geq f^{-}+\lambda^{ \pm}\left(f^{+}-f^{-}\right)$

$A^{ \pm} X^{ \pm} \leq B^{+}-\lambda^{ \pm}\left(B^{+}-B^{-}\right)$

$X^{ \pm} \geq 0$

$0 \leq \lambda^{ \pm} \leq 1$

where $f^{-}$and $f^{+}$are the lower and upper bounds of the objecttive's aspiration level (i.e. $f^{+}$is the most desirable system objective value; $f^{-}$is the least desirable system objective value), respectively; $\lambda^{ \pm}$is the control variable corresponding to the degree (membership grade) of satisfaction for the fuzzy decision. An interactive solution algorithm is developed to solve the above problem through analyzing the detailed interrelationships between the parameters and the variables and between the objective function and the constraints (Huang et al., 1993).

\subsection{Interval-Fuzzy De Novo Programming}

A De Novo programming model can be formulated as follows (Zeleny, 1990):

$\max Z=C x$

Subject to:

$$
\begin{aligned}
& A X-b \leq 0 \\
& p b \leq B \\
& x \geq 0
\end{aligned}
$$

where $C \in R^{k \times j}$ and $A \in R^{i \times j}$ are matrices of dimensions $k \times j$ and $i \times j$, respectively; $p\left(p=p_{1}, p_{2}, \ldots, p_{\mathrm{i}}\right)$ is the given unit prices of $i$ resources; $B$ is total given variable budget; $b\left(b=b_{1}\right.$, $b_{2}, \ldots, b_{\mathrm{i}}$ ) is the resulting (optimal) portfolio of resources, which can be considered as design decision variables in the above problem; $x$ is the production levels, $x=x_{1}, x_{2}, \ldots, x_{j}$, which can be regarded as management decision variables.

Incorporating IFLP within model (6), an interval-fuzzy De Novo programming (IFDNP) with single and/or multiple objectives for optimal system design can be formulated as follows:

$\max z^{ \pm} \equiv C^{ \pm} X^{ \pm}$ 
Subject to:

$A^{ \pm} X^{ \pm}-b^{ \pm} \leq 0$

$p^{ \pm} b^{ \pm} \lesssim B^{ \pm}$

$X^{ \pm} \geq 0$

where $C^{ \pm} \in R^{k \times j}$ and $A^{ \pm} \in R^{i \times j}$ are matrices of dimensions $k \times$ $j$ and $i \times j$, respectively; $c_{k j}^{ \pm}$is the element of matrix $C^{ \pm} ; a_{i j}^{ \pm}$is the element of matrix $A^{ \pm} ; b^{ \pm}$is a vector of design decision variables, $b^{ \pm}=\left(b_{1}^{ \pm}, b_{2}^{ \pm}, \ldots, b_{i}^{ \pm}\right) ; X^{ \pm}$is a vector of management decision variables, $X^{ \pm}=\left(x_{1}^{ \pm}, x_{2}^{ \pm}, \ldots, x_{j}^{ \pm}\right) ; p^{ \pm}$is the vector of the unit prices of $i$ resources, $p^{ \pm}=\left(p_{1}^{ \pm}, p_{2}^{ \pm}, \ldots, p_{i}^{ \pm}\right) ; B^{ \pm}$is the given total available budget.

According to Zimmermann (1995), decision makers may establish an aspiration level $\left(z^{ \pm}\right)$, and a tolerable interval $\left(\Delta z=z^{+}-z^{-}\right)$for the objective they desire to achieve, and each of the constraints can be modeled as a fuzzy set. Thus, to better communicate fuzzy objective and constraints, as well as the flow uncertainties, model (7) can be converted into the following formulation:

$\max \lambda^{ \pm}$

Subject to:

$$
\begin{aligned}
& C^{ \pm} X^{ \pm} \geq z^{-}+\lambda^{ \pm}\left(z^{+}-z^{-}\right) \\
& p^{ \pm} b^{ \pm} \leq B^{+}-\lambda^{ \pm}\left(B^{+}-B^{-}\right) \\
& A^{ \pm} X^{ \pm}-b^{ \pm} \leq 0 \\
& X^{ \pm} \geq 0 \\
& 0 \leq \lambda^{ \pm} \leq 1
\end{aligned}
$$

where $z^{-}$and $z^{+}$are the lower and upper bounds of the objective's aspiration level (i.e. $z^{+}$is the most desirable system objective value; $z^{-}$is the least desirable system objective value), respectively; $\lambda^{ \pm}$is a control variable, which denotes the degree of satisfaction for the fuzzy objective and/or constraints. A $\lambda^{ \pm}$level close to 1 would correspond to a high possibility of satisfying the constraints/objective under advantageous conditions; conversely, a $\lambda^{ \pm}$value near 0 would be related to a solution that has a low possibility of satisfying the constraints/objective under demanding conditions. Model (8) can deal with uncertainties described as intervals and fuzzy sets. These definitions are essential because there are two kinds of decision variables including design decision variables $b^{ \pm}$and management decision variables $x^{ \pm}$in the IFDNP model.

Then, model (8) can be solved through a two-step method by transforming into two sets of deterministic submo- dels, which correspond to the lower and upper bounds of the desired objective function value; this transformation process is based on an interactive algorithm, which is different from normal interval analysis and best/worst case analysis (Huang et al., 1993). In this study, an optimized set of $z^{ \pm}$values can be identified by having $b^{ \pm}$and $x^{ \pm}$being decision variables; this optimized set may correspond to maximum system objective value under the uncertain design decision variables and management decision variables. Thus, when $z^{ \pm}$approach their upper bounds (i.e. when $\lambda=1$ ), a relatively most desirable system objective value will be obtained if decision variables are satisfied; however, a high penalty may have to be paid when decision variables are not satisfied. Conversely, when $z^{ \pm}$reach their lower bounds (i.e. when $\lambda=0$ ), we may have a least desirable system objective value but, at the same time, a lower risk of violating the promised targets (and thus lower penalty). Therefore, model (8) can be transformed into two deterministic submodels based on the interactive algorithm. Because the objective is to maximize the objective function value, $z^{ \pm}$is first desired; the other submodel (correspondding to $z^{-}$) can then be formulated based on the solution of the first submodel. The upper bounds of positive coefficients and the lower bounds of negative coefficients correspond to $z^{+}$. The solutions provide intervals for the objective functions and decision variables associated with different constraint-violation levels. Thus, the first submodel for $\lambda^{+}$corresponding to $z^{+}$is (assume that $b_{i}>0$ ):

$\max \lambda^{+}$

Subject to:

$$
\begin{aligned}
& \sum_{j=1}^{t} c_{k j}^{+} x_{j}^{+}-\sum_{j=t+1}^{n} c_{k j}^{+} x_{j}^{-} \geq z_{k}^{-}+\lambda^{+}\left(z_{k}^{+}-z_{k}^{-}\right), \forall k \\
& \sum_{j=1}^{t}\left|p_{i}\right|^{-} \operatorname{Sign}\left(p_{i}^{-}\right)\left(\sum_{j=1}^{t}\left|a_{i j}\right|^{-} \operatorname{Sign}\left(a_{i j}^{-}\right) x_{j}^{+}\right)+\sum_{j=t+1}^{n}\left|p_{i}\right|^{-} \operatorname{Sign}\left(p_{i}^{-}\right) \\
& \left(\sum_{j=t+1}^{n}\left|a_{i j}\right|^{+} \operatorname{Sign}\left(a_{i j}^{+}\right) x_{j}^{-}\right) \leq B^{+}-\lambda^{+}\left(B^{+}-B^{-}\right), \forall i \\
& \sum_{j=1}^{t}\left|a_{i j}\right|^{-} \operatorname{Sign}\left(a_{i j}^{-}\right) x_{j}^{+}+\sum_{j=t+1}^{n}\left|a_{i j}\right|^{+} \operatorname{Sign}\left(a_{i j}^{+}\right) x_{j}^{-}-b_{i}^{+} \leq 0 \\
& x_{j}^{ \pm} \geq 0, \forall j \\
& 0 \leq \lambda^{+} \leq 1
\end{aligned}
$$

where $x_{j}^{+}, j=1,2, \ldots, t$, are interval variables with positive coefficients in the objective function; $x_{j}^{-}, j=t+1, t+2, \ldots$, $n$, are interval variables with negative coefficients in the objective function. Solutions of $x_{j}^{+}, x_{j}^{-}, b_{i}^{+}$and $\lambda^{+}$can be obtained from submodel (9). Let ${ }^{*} z_{k}^{ \pm}=\max z_{k}^{ \pm}, k=1, \ldots$, $q$, be the optimal value for Kth objective of submodel with model (9). Let ${ }^{*} z^{ \pm}=\left({ }^{*} z_{1}^{ \pm},{ }^{*} z_{2}^{ \pm}, \ldots,{ }^{*} z_{q}^{ \pm}\right)$be the $q$-objective value 
for the ideal system with respect to $B^{ \pm}$. Then, the metaoptimum submodel can be constructed as follows:

$\max { }^{*} \lambda^{+}$

Subject to:

$\sum_{j=1}^{t}\left|p_{i}\right|^{-} \operatorname{Sign}\left(p_{i}^{-}\right)\left(\left.\sum_{j=1}^{t}\left|a_{i j}\right|\right|^{-} \operatorname{Sign}\left(a_{i j}^{-}\right) x_{j}^{+}\right)+\sum_{j=t+1}^{n}\left|p_{i}\right|^{-} \operatorname{Sign}\left(p_{i}^{-}\right)$
$\left(\sum_{j=t+1}^{n}\left|a_{i j}\right|^{+} \operatorname{Sign}\left(a_{i j}^{+}\right) x_{j}^{-}\right) \leq{ }^{*} B^{+}-{ }^{*} \lambda^{+}\left({ }^{*} B^{+}-{ }^{*} B^{-}\right), \forall i$

$\sum_{j=1}^{t} c_{k j}^{+} x_{j}^{+}-\sum_{j=t+1}^{n} c_{k j}^{+} x_{j}^{-} \geq{ }^{*} z_{k}^{-}+{ }^{*} \lambda^{+}\left({ }^{*} z_{k}^{+}-{ }^{*} z_{k}^{-}\right), \forall k$

$x_{j}^{ \pm} \geq 0$

$0 \leq{ }^{*} \lambda^{+} \leq 1$

Solving model (10) yields ${ }^{*} x_{j}^{ \pm},{ }^{*} b^{+},{ }^{*} \lambda^{+}$and ${ }^{*} r^{+}$, where:

${ }^{*} b^{+}=\sum_{j=1}^{t}\left|a_{i j}\right|^{-} \operatorname{Sign}\left(a_{i j}^{-}\right)^{*} x_{j}^{+}+\sum_{j=t+1}^{n}\left|a_{i j}\right|^{+} \operatorname{Sign}\left(a_{i j}^{+}\right)^{*} x_{j}^{-}$

${ }^{*} r^{+}=\frac{\sum \omega_{s} B_{s}^{+}}{{ }^{*} B^{+}}$

The value $B_{s}^{+}$is the budget level of producing ${ }^{*} x_{j}^{ \pm}$with respect to the $S$ th objective, where $\sum \omega_{s}=1$ and $0 \leq \omega_{s} \leq 1$ (Shi, 1995). The optimal system design can be established as $\left(x_{o p t}^{ \pm}, b_{o p t}^{+}, z_{o p t}^{+}\right)$, where $\lambda_{o p t}^{+}={ }^{*} \lambda^{+}, x_{o p t}^{+}={ }^{*} r^{+} \times{ }^{*} x_{j}^{+}, \quad(j=1$, $2, \ldots, t), x_{o p t}^{-}={ }^{*} r^{+} x^{*} x_{j}^{-},(j=t+1, t+2, \ldots, n)$, $b_{o p t}^{+}={ }^{*} r^{+} \times{ }^{*} b^{+}$, and $z_{o p t}^{+}={ }^{*} r^{+} \times{ }^{*} z_{k}^{+}$. The optimum-path ratio ${ }^{*} r^{+}$provides an effective and fast tool for optimal redesign of large-scale systems. Based on the above solutions, the second submodel for $\lambda^{-}$(corresponding to $z^{-}$) can be formulated as follows (assume that $b_{i}>0$ ):

$\max \lambda^{-}$

Subject to:

$\sum_{j=1}^{t} c_{k j}^{-} x_{j}^{-}-\sum_{j=t+1}^{n} c_{k j}^{-} x_{j}^{+} \geq z_{k}^{-}+\lambda^{-}\left(z_{k}^{-}-z_{k}^{-}\right), \forall k$

$\sum_{j=1}^{t}\left|p_{i}\right|^{+} \operatorname{Sign}\left(p_{i}^{+}\right)\left(\sum_{j=1}^{t}\left|a_{i j}\right|^{+} \operatorname{Sign}\left(a_{i j}^{+}\right) x_{j}^{-}\right)+\sum_{j=t+1}^{n}\left|p_{i}\right|^{+} \operatorname{Sign}\left(p_{i}^{+}\right)$

$\left(\sum_{j=t+1}^{n}\left|a_{i j}\right|^{-} \operatorname{Sign}\left(a_{i j}^{-}\right) x_{j}^{+}\right) \leq B^{+}-\lambda^{-}\left(B^{+}-B^{-}\right), \forall i$

$\sum_{j=1}^{t}\left|a_{i j}\right|^{+} \operatorname{Sign}\left(a_{i j}^{+}\right) x_{j}^{-}+\sum_{j=t+1}^{n}\left|a_{i j}\right|^{-} \operatorname{Sign}\left(a_{i j}^{-}\right) x_{j}^{+}-b_{i}^{-} \leq 0$ $z_{k}^{-} \leq^{*} z_{k}^{+}, \forall k$

$x_{j}^{ \pm} \geq 0, \forall j$

$0 \leq \lambda^{-} \leq 1$

where $x_{j}^{-}, j=1,2, \ldots, t$, are interval variables with positive coefficients in the objective function; $x_{j}^{+}, j=t+1, t+2, \ldots$, $n$, are interval variables with negative coefficients in the objective function. Solution of $x_{j}^{-}, x_{j}^{+}, b_{i}^{-}$and $\lambda^{-}$can be obtained through solving submodel (12). Similarly, the metaoptimum submodel can be constructed as follows:

$\max { }^{*} \lambda^{-}$

Subject to:

$\sum_{j=1}^{t}\left|p_{i}\right|^{+} \operatorname{Sign}\left(p_{i}^{+}\right)\left(\sum_{j=1}^{t}\left|a_{i j}\right|^{+} \operatorname{Sign}\left(a_{i j}^{+}\right) x_{j}^{-}\right)+\sum_{j=t+1}^{n}\left|p_{i}\right|^{+} \operatorname{Sign}\left(p_{i}^{+}\right)$

$\left(\sum_{j=t+1}^{n}\left|a_{i j}\right|^{-} \operatorname{Sign}\left(a_{i j}^{-}\right) x_{j}^{+}\right) \leq{ }^{*} B^{+}-{ }^{*} \lambda^{-}\left({ }^{*} B^{+}-{ }^{*} B^{-}\right), \forall i$

$\sum_{j=1}^{t} c_{k j}^{-} x_{j}^{-}-\sum_{j=t+1}^{n} c_{k j}^{-} x_{j}^{+} \geq{ }^{*} z_{k}^{-}+{ }^{*} \lambda^{-}\left({ }^{*} z_{k}^{+}-{ }^{*} z_{k}^{-}\right), \forall k$

$x_{j}^{ \pm} \geq 0$

$x_{j}^{-} \leq{ }^{*} x_{j}^{+}, j=1,2, \ldots, t$

$x_{j}^{+} \geq{ }^{*} x_{j}^{-}, j=t+1, t+2, \ldots, n$

$0 \leq{ }^{*} \lambda^{-} \leq 1$

Solving model (13) yields ${ }^{*} x_{j}^{ \pm},{ }^{*} b^{-},{ }^{*} \lambda^{-}$and ${ }^{*} r^{-}$, where:

${ }^{*} b^{-}=\sum_{j=1}^{t}\left|a_{i j}\right|^{+} \operatorname{Sign}\left(a_{i j}^{+}\right)^{*} x_{j}^{-}+\sum_{j=t+1}^{n}\left|a_{i j}\right|^{-} \operatorname{Sign}\left(a_{i j}^{-}\right)^{*} x_{j}^{+}$

${ }^{*} r^{-}=\frac{\sum \omega_{s} B_{s}^{-}}{{ }^{*} B^{-}}$

where $B_{s}^{-}$is the budget level of producing ${ }^{*} x_{j}^{ \pm}$with respect to the $S$ th objective, with $\sum \omega_{s}=1$ and $0 \leq \omega_{s} \leq 1$ (Shi, 1995). The optimal system design can be established as $\left(x_{o p t}^{ \pm}, b_{o p t}^{-}\right.$, $\left.z_{\text {opt }}^{-}\right)$, where $\lambda_{\text {opt }}^{-}={ }^{*} \lambda^{-}, x_{\text {opt }}^{-}={ }^{*} r^{-} \times{ }^{*} x_{j}^{-},(j=1,2, \ldots, t), x_{o p t}^{+}=$ ${ }^{*} r^{-} \times{ }^{*} x_{j}^{+},(j=t+1, t+2, \ldots, n), b_{o p t}^{-}={ }^{*} r^{-} \times{ }^{*} b^{-}$, and $z_{o p t}^{-}=$ ${ }^{*} r^{-} \times{ }^{*} z_{k}^{-}$.

Therefore, $b_{o p t}^{+}, z_{o p t}^{+}, x_{o p t}^{+}(j=1,2, \ldots, t)$ and $x_{o p t}^{-}(j=t+$ $1, t+2, \ldots, n)$ can be obtained by solving the submodel defined by models (9) to (11), whereas $b_{o p t}^{-}, z_{o p t}^{-}, x_{o p t}^{-}$ $(j=1,2, \ldots, t)$ and $x_{o p t}^{+}(j=t+1, t+2, \ldots, n)$ can be obtained 
from models (12) to (14). Figure 1 summarizes the scheme of the IFDNP model. Final solutions for model (8) are:

$$
\begin{aligned}
& x_{o p t}^{ \pm}=\left[x_{o p t}^{-}, x_{o p t}^{+}\right] \\
& \lambda_{o p t}^{ \pm}=\left[\lambda_{o p t}^{-}, \lambda_{o p t}^{+}\right] \\
& z_{o p t}^{ \pm}=\left[z_{o p t}^{-}, z_{o p t}^{+}\right] \\
& b_{o p t}^{ \pm}=\left[b_{o p t}^{-}, b_{o p t}^{+}\right]
\end{aligned}
$$

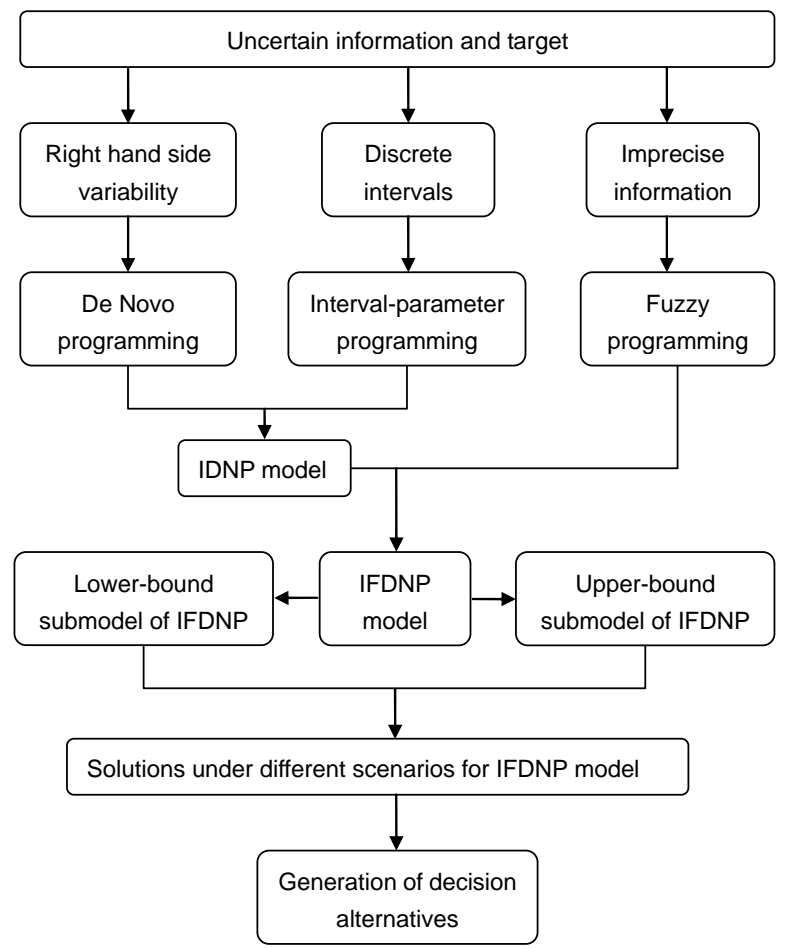

Figure 1. Schematic of the IFDNP method.

\subsection{A Numerical Example}

To illustrate the developed IFDNP method, a numerical example is introduced. Consider a case where the decision makers want to maximize the economic benefit and environmental protection benefit of two districts in a big agricultural farm by allocating necessary electric and water resources. However, the total budget is limited within [40,48] million dollars. Let $x_{1}, x_{2}$ represent the farming area of two districts and $b_{1}, b_{2}$ represent the total electric and water cost consumed by $x_{1}, x_{2}$, respectively with the price of 1 /unit and 0.8 /unit under the total resource-consuming budget. The detailed description of this example is as follows:

$\max z_{1}^{ \pm}=[1.5,2] x_{1}^{ \pm}+[2,3] x_{2}^{ \pm}$

$\max z_{2}^{ \pm}=[2,3] x_{1}^{ \pm}+[0.6,1] x_{2}^{ \pm}$
Subject to:

$$
\begin{aligned}
& {[2,2.5] x_{1}^{ \pm}+[1.5,2] x_{2}^{ \pm} \leq b_{1}^{ \pm}} \\
& {[1.5,2] x_{1}^{ \pm}+[2,2.5] x_{2}^{ \pm} \leq b_{2}^{ \pm}} \\
& b_{1}^{ \pm}+0.8 b_{2}^{ \pm} \leq[40,48] \\
& x_{1}^{ \pm} \leq 7.2 \\
& x_{2}^{ \pm} \leq 9
\end{aligned}
$$

Table 1. Values of Symbols in Upper-Bound Model (9)

\begin{tabular}{llllll}
\hline $\mathrm{z}_{\mathrm{k}}^{+}$ & & $\mathrm{x}_{\mathrm{j}}^{+}(\mathrm{j}=1)$ & \multicolumn{3}{c}{$\mathrm{x}_{\mathrm{j}}^{+}(\mathrm{j}=2)$} \\
\hline $\mathrm{z}_{1}^{+}(\mathrm{k}=1)$ & $\mathrm{c}_{\mathrm{kj}}{ }^{+}$ & $\mathrm{c}_{11}{ }^{+}$ & 2 & $\mathrm{c}_{12}{ }^{+}$ & 3 \\
$\mathrm{z}_{2}^{+}(\mathrm{k}=2)$ & $\mathrm{c}_{\mathrm{kj}}{ }^{+}$ & $\mathrm{c}_{21}{ }^{+}$ & 3 & $\mathrm{c}_{22}{ }^{+}$ & 1 \\
$\mathrm{~b}_{\mathrm{i}}{ }^{+}(\mathrm{i}=1)$ & $\left|\mathrm{a}_{\mathrm{ij}}\right|^{-}$ & $\left|\mathrm{a}_{11}\right|^{-}$ & 2 & $\left|\mathrm{a}_{12}\right|^{-}$ & 1.5 \\
& $\operatorname{Sign}\left(\mathrm{a}_{\mathrm{ij}}{ }^{-}\right)$ & $\operatorname{Sign}\left(\mathrm{a}_{11}{ }^{-}\right)$ & + & $\operatorname{Sign}^{-}\left(\mathrm{a}_{12}{ }^{-}\right)$ & + \\
$\mathrm{b}_{\mathrm{i}}{ }^{+}(\mathrm{i}=2)$ & $\left|\mathrm{a}_{\mathrm{ij}}\right|^{-}$ & $\left|\mathrm{a}_{21}\right|^{-}$ & 1.5 & $\left|\mathrm{a}_{22}\right|^{-}$ & 2 \\
& $\operatorname{Sign}\left(\mathrm{a}_{\mathrm{ij}}{ }^{-}\right)$ & $\operatorname{Sign}\left(\mathrm{a}_{21}{ }^{-}\right)$ & + & $\operatorname{Sign}^{-}\left(\mathrm{a}_{22}{ }^{-}\right)$ & + \\
\hline
\end{tabular}

Table 2. Values of Symbols in Lower-Bound Model (12)

\begin{tabular}{llllll}
\hline $\mathrm{z}_{\mathrm{k}}{ }^{-}$ & & $\mathrm{x}_{\mathrm{j}}^{-}(\mathrm{j}=1)$ & \multicolumn{3}{c}{$\mathrm{x}_{\mathrm{j}}^{-}(\mathrm{j}=2)$} \\
\hline $\mathrm{z}_{1}^{-}(\mathrm{k}=1)$ & $\mathrm{c}_{\mathrm{kj}}{ }^{-}$ & $\mathrm{c}_{11}{ }^{-}$ & 1.5 & $\mathrm{c}_{12}{ }^{-}$ & 2 \\
$\mathrm{z}_{2}^{-}(\mathrm{k}=2)$ & $\mathrm{c}_{\mathrm{kj}}{ }^{-}$ & $\mathrm{c}_{21}{ }^{-}$ & 2 & $\mathrm{c}_{22}{ }^{-}$ & 0.6 \\
$\mathrm{~b}_{\mathrm{i}}^{-}(\mathrm{i}=1)$ & $\left|\mathrm{a}_{\mathrm{ijj}}\right|^{+}$ & $\left|\mathrm{a}_{11}\right|^{+}$ & 2.5 & $\left|\mathrm{a}_{12}\right|^{+}$ & 2 \\
& $\operatorname{Sign}^{+}\left(\mathrm{a}_{\mathrm{ij}}{ }^{+}\right)$ & $\operatorname{Sign}\left(\mathrm{a}_{11}{ }^{+}\right)$ & + & $\left.\operatorname{Sign} \mathrm{a}_{12}{ }^{+}\right)$ & + \\
$\mathrm{b}_{\mathrm{i}}{ }^{-}(\mathrm{i}=2)$ & $\left|\mathrm{a}_{\mathrm{ij}}\right|^{+}$ & $\left|\mathrm{a}_{21}\right|^{+}$ & 2 & $\left|\mathrm{a}_{22}\right|^{+}$ & 2.5 \\
& $\operatorname{Sign}\left(\mathrm{a}_{\mathrm{ij}}{ }^{+}\right)$ & $\operatorname{Sign}\left(\mathrm{a}_{21}{ }^{+}\right)$ & + & $\operatorname{Sign}^{+}\left(\mathrm{a}_{22}{ }^{+}\right)$ & + \\
\hline
\end{tabular}

Assume that the objective functions of $z_{1}^{ \pm}$and $z_{2}^{ \pm}$are equally important. From model (9), the submodel correspondding to $z^{+}$can be first formulated. The corresponding values for symbols of model (9) are listed in Table 1.

$\max \lambda_{1}^{+}$

$\max \lambda_{2}^{+}$

Subject to:

$$
\begin{aligned}
& 2 x_{1}^{+}+3 x_{2}^{+} \geq 14.63+\lambda_{1}^{+}(38.85-14.63) \\
& 3 x_{1}^{+}+x_{2}^{+} \geq 13.85+\lambda_{2}^{+}(29.11-13.85) \\
& b_{1}^{+}+0.8 b_{2}^{+} \leq 48-\lambda_{1,2}^{+}(48-40) \\
& 2 x_{1}^{+}+1.5 x_{2}^{+} \leq b_{1}^{+} \\
& 1.5 x_{1}^{+}+2 x_{2}^{+} \leq b_{2}^{+} \\
& x_{1}^{+} \leq 7.2
\end{aligned}
$$


$x_{2}^{+} \leq 9$

$0 \leq \lambda_{1,2}^{+} \leq 1$

By solving submodel (20), we can obtain $\lambda_{1}^{+}, \lambda_{2}^{+}=(0.85$, $0.89)$ and $x_{1}^{+}, x_{2}^{+}=(4.15,5.77)$. Then, based on model $(12)$, the submodel corresponding to $z^{-}$can be formulated as follows:

$\max \lambda_{1}^{-}$

$\max \lambda_{2}^{-}$

Subject to:

$$
\begin{aligned}
& 1.5 x_{1}^{-}+2 x_{2}^{-} \geq 14.63+\lambda_{1}^{-}(38.85-14.63) \\
& 2 x_{1}^{-}+0.6 x_{2}^{-} \geq 13.85+\lambda_{2}^{-}(29.11-13.85) \\
& b_{1}^{-}+0.8 b_{2}^{-} \leq 48-\lambda_{1,2}^{-}(48-40) \\
& 2.5 x_{1}^{-}+2 x_{2}^{-} \leq b_{1}^{-} \\
& 2 x_{1}^{-}+2.5 x_{2}^{-} \leq b_{2}^{-} \\
& x_{1}^{-} \leq x_{1}^{+} \\
& x_{2}^{-} \leq x_{2}^{+} \\
& 0 \leq \lambda_{1,2}^{-} \leq 1
\end{aligned}
$$

The values of symbols are shown in Table 2. By solving submodel (21), we can obtain $\lambda_{1}^{-}, \lambda_{2}^{-}=(0.29,0.20)$ and $x_{1}^{-}, x_{2}^{-}=(2.37,4.22)$. From the results of submodel $(20)$, a metaopti mum submodel can be constructed as follows:

$\max { }^{*} \lambda^{+}$

Subject to:

$1 \times\left(2 x_{1}^{+}+1.5 x_{2}^{+}\right)+0.8 \times\left(1.5 x_{1}^{+}+2 x_{2}^{+}\right) \leq 48.87-{ }^{*} \lambda^{+}(48.87-$ 46.12)

$2 x_{1}^{+}+3 x_{2}^{+} \geq 11.99+{ }^{*} \lambda^{+}(25.59-11.99)$

$3 x_{1}^{+}+x_{2}^{+} \geq 7.27+{ }^{*} \lambda^{+}(18.21-7.27)$

$0 \leq{ }^{*} \lambda^{+} \leq 1$

Solving the metaoptimum submodel, we can obtain ${ }^{*} \lambda^{+}=0.98$ and ${ }^{*} x_{1}^{+},{ }^{*} x_{2}^{+}=(5.20,9.0)$. Because the optimal-path ratio $r=\sum \omega_{s} B_{s} / B^{*}$, with $\sum \omega_{s}=1$ and $0 \leq \omega_{s} \leq 1$, and we let $\omega_{1}=1 / 2, \omega_{2}=1 / 2$, respectively. The optimal-path ratio ${ }^{*} r^{+}=$ $(1 / 2 \times 23.9+1 / 2 \times 20.64) / 48.87=45.6 \%$, the resulting $\lambda_{\text {opt }}^{+}={ }^{*} \lambda^{+}, x_{1 \text { opt }}^{+}, x_{2 o p t}^{+}=(2.16,4.10), z_{1 o p t}^{+}, z_{2 o p t}^{+}=(17.04$, $11.21)$ and $b_{1 \text { opt }}^{+}, b_{2 o p t}^{+}=(10.89,11.76)$, respectively.

Based on the results of submodel (21), a metaoptimum sub-model can be constructed as follows:

$\max { }^{*} \lambda^{-}$

Subject to:

$1 \times\left(2.5 x_{1}^{-}+2 x_{2}^{-}\right)+0.8 \times\left(2 x_{1}^{-}+2.5 x_{2}^{-}\right) \leq 48.87-{ }^{*} \lambda^{-}(48.87-$

$46.12)$

$1.5 x_{1}^{-}+2 x_{2}^{-} \geq 11.99+{ }^{*} \lambda^{-}(25.59-11.99)$

$2 x_{1}^{-}+0.6 x_{2}^{-} \geq 7.27+{ }^{*} \lambda^{-}(18.21-7.27)$

$x_{1}^{-} \leq x_{1}^{+}$

$x_{2}^{-} \leq x_{2}^{+}$

$0 \leq \lambda^{*} \leq 1$

Solving the metaoptimum submodel, we can obtain ${ }^{*} \lambda^{-}=0.64$ and $^{*} x_{1}^{-},{ }^{*} x_{2}^{-}=(3.07,6.45)$. Similarly, the optimalpath ratio ${ }^{*} r^{-}=19.19 / 46.12=41.6 \%$, and the resulting $\lambda_{\text {opt }}^{-}={ }^{*} \lambda^{-}, x_{1 o p t}^{-}, x_{2 o p t}^{-}=(1.40,2.68), z_{1 o p t}^{-}, z_{2 o p t}^{-}=(7.28,4.16)$ and $b_{1 \text { opt }}^{-}, b_{2 \text { opt }}^{-}=(8.56,9.26)$, respectively. Then the final solutions are: $\lambda_{\text {opt }}^{ \pm}=[0.64,0.98], x_{1 o p t}^{ \pm}=[1.40,2.16], x_{2 o p t}^{ \pm}$ $=[2.68,4.10], z_{1 \text { opt }}^{ \pm}=[7.28,17.04], z_{2 o p t}^{ \pm}=[4.16,11.21]$, $b_{1 \text { opt }}^{ \pm}=[8.56,10.89], b_{2 o p t}^{ \pm}=[9.26,11.76]$. The results show that the planned farming areas of two districts are [1.40, 2.16] and $[2.68,4.10] \mathrm{km}^{2}$. Under the budget of $[40,48]$ million dollars, the allocated funds to electric and water consumption are $[8.56,10.89]$ and $[9.26,11.76]$ million dollars, respecttively. The economic and environmental benefits are [7.28, $17.04]$ and $[4.16,11.21]$ million dollars, respectively.

\section{Case Study}

For many decades, water resources planning problems, such as the efficient allocation of water and reasonable water treatment plant design, have challenged water resource managers in generating optimal or compromise decisions (Maqsood et al., 2005). It is essential for the decision makers to gain a better understanding of system components and their interrelationships within water resources systems so as to meet their objectives. In many practical cases, the complexity of the system and the limited knowledge are the main obstacles to obtainning appropriate decision alternatives in a conflicting objective environment (Huang et al., 2010). Most of the previous planning problems focused on optimal water alloca- 
tion and did not consider the initial planning problems such as design of water resources systems including determining the maximum treatment ability of water plants, capability of reservoirs (Zhang et al., 2009). The following water resources management problem will be used to demonstrate applicability of the developed IFDNP approach.

Consider a case in which a manager is responsible for allocating water from a reservoir for two cities to three users: a municipality, an industrial unit, and an agricultural sector (Figure 2). The shrinking water availability has been exacerbating such competitions, particularly under varying natural conditions and deteriorating quantity and quality of water resources. Therefore, all users want to know how much water they can expect. If insufficient water is available, they will try to obtain water from other sources or curtail their development plans. The system budget is $[550,700] \times 10^{6}$ dollars including expenses for water supply and water treatment. The unit benefit and price of each water user are listed in Table 3 . The minimum total water needs and minimum proportions of total allocated water to three users in two cities are deliberated (Table 3). In urban water system design, it is necessary to guarantee that the water allocation must meet the least demand of each city and each user (Su et al., 2011). To guarantee quantity and quality of water, different treatment facilities for different users are investigated. Therefore, the problems under consideration are how to effectively allocate water to the three users to achieve a maximum benefit under uncertainty while incorporating water policies with the least risk of system disruption. Based on the IFDNP, the study problem can be formulated as follows:

$\max \lambda^{ \pm}$

Subject to:

(1) Maximize benefits for each water user:

$\sum_{i=1}^{m} c_{i j}^{ \pm} x_{i j}^{ \pm} \geq z_{j}^{-}+\lambda^{ \pm}\left(z_{j}^{+}-z_{j}^{-}\right), \forall j$

(2) Treated water demand of city:

$\sum_{j=1}^{n} a_{i j}^{ \pm} x_{i j}^{ \pm}-b_{i}^{ \pm} \leq 0, \forall i$

(3) Total water needs of end user:

$\sum_{i=1}^{m} x_{i j}^{ \pm} \leq b_{j}^{ \pm}, \forall j$

(4) Budget limit for water system design:

$\sum_{i=1}^{m} p_{i}^{ \pm} b_{i}^{ \pm}+\sum_{j=1}^{n} p_{j}^{ \pm} b_{j}^{ \pm} \leq B^{+}-\lambda^{ \pm}\left(B^{+}-B^{-}\right)$
(5) Minimum water allocation to city:

$\sum_{i=1}^{m} x_{i j}^{ \pm} \geq l_{i}^{ \pm}, \forall i$

(6) Minimum proportion of total allocated water to end users in city $i$ :

$x_{i j}^{ \pm} \geq e_{i j}^{ \pm} \sum_{i=1}^{m} x_{i j}^{ \pm}, \forall i, j$

(7) Minimum water allocation to end users in city $i$ :

$x_{i j}^{ \pm} \geq q_{i j}^{ \pm}, \forall i, j$

where $c_{i j}^{ \pm}$is the unit benefit of water user $j$ in city $i, i=1,2$; $j=1,2,3 ; z_{j}^{ \pm}$is maximize benefit for each water user $j ; a_{i j}^{ \pm}$is water treatment efficiency for water usage $j$ in city $i ; l_{i}^{ \pm}$is the least total water allocation to city $i ; q_{i j}^{ \pm}$and $e_{i j}^{ \pm}$are the minimum water needs and minimum proportions of total allocated water to city for user $j ; x_{i j}^{ \pm}$is decision variable of water allocation plan to user $j$ in city $i ; b_{i}^{ \pm}$is the design variable for total water allocation to city $i$ which is corresponding to unit cost $p_{i}$ within the total water usage budget; $b_{j}^{ \pm}$is the design variable of water treatment capacity for water user $j$, which correspond to unit cost $p_{j}$ within the total water usage budget.

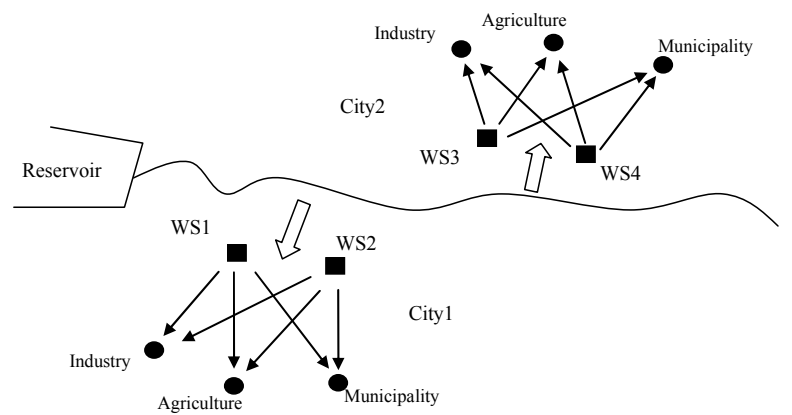

Figure 2. Schematic of water allocation to multiple users.

In regional water resources planning problems, optimal supplies of high-quality water will be emphasized due to conflicting revenue target of municipal-industrial-agricultural balance under a given construction budget of water treatment facilities. It is desired that water treatment facilities for municipality, industry and agriculture be effectively designed for supporting sustainable management of available water resources. In order to balance the earnings of the competitive water users under the limited water budget, it is recognized that the different objectives of users should be considered in relation to each other. Moreover, in various real world cases, uncertainties are associated with a number of impact factors such as cost and water treatment efficiency (Huang et al., 2010). As a result, how to optimally design water resources systems under 
uncertainty is one main challenge for decision makers. Decision makers often pay more attention to the optimal system design at the initial planning stage instead of just selecting the optimal allocation alternatives from predeter mined data sets.

Table 3. Inputs of Model (24)

\begin{tabular}{lcll}
\hline Benefit $\left(\$ / \mathrm{m}^{3}\right)$ & Industry & Municipality & Agriculture \\
\hline City 1 & {$[80,90]$} & {$[76,80]$} & {$[45,50]$} \\
City 2 & {$[92,100]$} & {$[70,75]$} & {$[40,43]$} \\
$\begin{array}{l}\text { Least water demand }\left(10^{6} \mathrm{~m}^{3}\right) \\
\text { City 1 }\end{array}$ & {$[13,15]$} & {$[13,15]$} & {$[13,15]$} \\
$\begin{array}{l}\text { City 2 } \\
\text { Least allocation proportion }\end{array}$ & {$[15,17]$} & {$[15,17]$} & {$[15,17]$} \\
$\begin{array}{l}\text { City 1 } \\
\text { City 2 }\end{array}$ & {$[0.30,0.32]$} & {$[0.25,0.27]$} & {$[0.35,0.36]$} \\
Water treatment efficiency & {$[0.35,0.37]$} & {$[0.20,0.23]$} & {$[0.30,0.32]$} \\
City 1 & {$[0.79,0.81]$} & {$[0.65,0.70]$} & {$[0.88,0.90]$} \\
City 2 & {$[0.85,0.88]$} & {$[0.70,0.75]$} & {$[0.93,0.95]$} \\
Price/unit water $\left(\$ / \mathrm{m}^{3}\right)$ & {$[1.5,1.8]$} & {$[2.0,2.1]$} & {$[1.0,1.3]$} \\
\hline \multicolumn{4}{c}{ City 2 } \\
\hline Least total water & City 1 & {$[65,70]$} \\
demand $\left(10^{6} \mathrm{~m}^{3}\right)$ & {$[55,60]$} & {$[2.0,2.3]$} \\
Price/unit water $\left(\$ / \mathrm{m}^{3}\right)$ & {$[2.5,2.7]$} & \multicolumn{2}{c}{} \\
\hline
\end{tabular}

\section{Results and Discussion}

\subsection{Result Analysis}

In this study, a number of scenarios associated with different optimum-path ratios are examined. According to different $\omega$ which values from 0.1 to 0.9 , we can obtain different optimum-path ratios corresponding to different scenarios. For example, the solutions from model (24) under scenario 5 (i.e. when $\omega_{1}=0.5$ and $\omega_{2}=0.5$ obtained optimumpath ratios ${ }^{*} r^{+}=0.21$ and ${ }^{*} r^{-}=0.20$; where $\omega 1$ is budget of two cities' weight coefficient and $\omega_{2}$ is budget of three water users' weight coefficient, respectively.) are shown in Table 5. For instance, for city 1, water flows allocated to industry, municipality and agriculture would be $[43.22,51.05] \times 10^{6}$

Table 4. Solutions from the IFDNP Model under Scenario 1

\begin{tabular}{|c|c|c|c|}
\hline Water user & Industry & Municipality & Agriculture \\
\hline $\begin{array}{l}\text { Water allocation } \\
\text { to city } 1\left(10^{6} \mathrm{~m}^{3}\right)\end{array}$ & $\begin{array}{l}{[57.91} \\
66.13]\end{array}$ & $\begin{array}{l}{[37.67,} \\
40.25]\end{array}$ & $\begin{array}{l}{[46.81} \\
52.95]\end{array}$ \\
\hline $\begin{array}{l}\text { Water allocation } \\
\text { to city } 2\left(10^{6} \mathrm{~m}^{3}\right)\end{array}$ & $\begin{array}{l}{[52.12} \\
57.50]\end{array}$ & $\begin{array}{l}{[40.18,} \\
43.69]\end{array}$ & $\begin{array}{l}{[54.43,} \\
59.39]\end{array}$ \\
\hline $\begin{array}{l}\text { Water treatment } \\
\text { limit } b_{j}\left(10^{6} \mathrm{~m}^{3}\right)\end{array}$ & $\begin{array}{l}\text { [92.78, } \\
101.11]\end{array}$ & $\begin{array}{l}{[56.51} \\
56.75]\end{array}$ & $\begin{array}{l}\text { [93.84, } \\
101.83]\end{array}$ \\
\hline \multirow[t]{2}{*}{$\begin{array}{l}\text { Net benefits } \\
\left(10^{6} \$\right)\end{array}$} & $\begin{array}{l}{[4560.12} \\
5289.96]\end{array}$ & $\begin{array}{l}\text { [2668.77, } \\
\text { 3058.59] }\end{array}$ & $\begin{array}{l}{[2061.89} \\
2375.59]\end{array}$ \\
\hline & City 1 & \multicolumn{2}{|l|}{ City 2} \\
\hline $\begin{array}{l}\text { Water supply } \\
\text { design } b_{i}\left(10^{6} \mathrm{~m}^{3}\right)\end{array}$ & {$[115.41,125.0]$} & \multirow{3}{*}{\multicolumn{2}{|c|}{$[127.72,134.69]$}} \\
\hline$\lambda_{\text {opt }}^{ \pm}$ & {$[0.73,0.99]$} & & \\
\hline$\lambda_{\text {meta }}{ }^{ \pm}\left(\mathrm{r} \cdot \lambda_{\text {opt }}{ }^{ \pm}\right)$ & {$[0.20,0.27]$} & & \\
\hline
\end{tabular}

Table 5. Solutions from the IFDNP Model under Scenario 5

\begin{tabular}{llll}
\hline Water user & Industry & Municipality & Agriculture \\
\hline Water allocation & {$[43.22$,} & {$[28.11$,} & {$[34.94$,} \\
to city $1\left(10^{6} \mathrm{~m}^{3}\right)$ & $51.05]$ & $31.07]$ & $40.88]$ \\
Water allocation & {$[38.90$,} & {$[30.00$,} & {$[40.62$,} \\
to city $2\left(10^{6} \mathrm{~m}^{3}\right)$ & $44.39]$ & $33.73]$ & $45.85]$ \\
Water treatment & {$[69.24$,} & {$[41.72$,} & {$[70.03$,} \\
limit $\mathrm{b}_{\mathrm{j}}\left(10^{6} \mathrm{~m}^{3}\right)$ & $78.07]$ & $44.28]$ & $78.62]$ \\
Net benefits $\left(10^{6}\right.$ & {$[3403.07$,} & {$[1991.62$,} & {$[1538.73$,} \\
$\$)$ & $4084.16]$ & $2361.41]$ & $1834.10]$ \\
\hline \multicolumn{3}{c}{ City 1} & \multicolumn{2}{c}{ City 2 } \\
\hline Water supply & {$[86.13,96.51]$} & {$[95.31,103.99]$} \\
design $\mathrm{b}_{\mathrm{i}}\left(10^{6} \mathrm{~m}^{3}\right)$ & \multicolumn{3}{|}{} \\
$\lambda_{\text {opt }}$ & {$[0.73,0.99]$} & \\
$\left.\lambda_{\text {meta }}{ }^{ \pm}{ }^{*} \mathrm{r} \cdot \lambda_{\text {opt }}{ }^{ \pm}\right)$ & {$[0.15,0.21]$} & & \\
\hline
\end{tabular}

Table 6. Solutions from the IFDNP Model under Scenario 9

\begin{tabular}{|c|c|c|c|}
\hline Water user & Industry & Municipality & Agriculture \\
\hline $\begin{array}{l}\text { Water allocation } \\
\text { to city } 1\left(10^{6} \mathrm{~m}^{3}\right)\end{array}$ & $\begin{array}{l}{[29.82,} \\
33.79]\end{array}$ & $\begin{array}{l}{[19.04,} \\
20.57]\end{array}$ & $\begin{array}{l}{[24.11,} \\
27.06]\end{array}$ \\
\hline $\begin{array}{l}\text { Water allocation } \\
\text { to city } 2\left(10^{6} \mathrm{~m}^{3}\right)\end{array}$ & $\begin{array}{l}{[26.84,} \\
29.38]\end{array}$ & $\begin{array}{l}{[20.69,} \\
22.33]\end{array}$ & $\begin{array}{l}{[28.03,} \\
30.35]\end{array}$ \\
\hline $\begin{array}{l}\text { Water treatment } \\
\text { limit } b_{j}\left(10^{6} \mathrm{~m}^{3}\right)\end{array}$ & $\begin{array}{l}{[47.77,} \\
51.67]\end{array}$ & $\begin{array}{l}{[29.00} \\
29.10]\end{array}$ & $\begin{array}{l}{[48.32} \\
52.04]\end{array}$ \\
\hline \multirow[t]{2}{*}{$\begin{array}{l}\text { Net benefits } \\
\left(10^{6} \$\right)\end{array}$} & $\begin{array}{l}{[2348.12,} \\
2703.33]\end{array}$ & $\begin{array}{l}{[1374.22,} \\
1563.03]\end{array}$ & $\begin{array}{l}{[1061.72,} \\
1214.00]\end{array}$ \\
\hline & City 1 & \multicolumn{2}{|c|}{ City 2} \\
\hline $\begin{array}{l}\text { Water supply } \\
\text { design } b_{i}\left(10^{6} \mathrm{~m}^{3}\right)\end{array}$ & {$[59.43,63.88]$} & \multirow{3}{*}{\multicolumn{2}{|c|}{$[65.76,68.83]$}} \\
\hline$\lambda_{\text {opt }}^{ \pm}$ & {$[0.73,0.99]$} & & \\
\hline$\lambda_{\text {meta }}{ }^{ \pm}\left({ }^{*} \mathrm{r} \cdot \lambda_{\text {opt }}{ }^{ \pm}\right)$ & {$[0.10,0.14]$} & & \\
\hline
\end{tabular}

$\mathrm{m}^{3},[28.11,31.07] \times 10^{6} \mathrm{~m}^{3}$ and $[34.94,40.88] \times 10^{6} \mathrm{~m}^{3}$, respectively; in comparison, water supply design budget variable would be $[86.13,96.51] \times 10^{6} \mathrm{~m}^{3}$. For city 2 , water flows allocated to industry, municipality and agriculture would be $[38.90,44.39] \times 10^{6} \mathrm{~m}^{3},[30.00,33.73] \times 10^{6} \mathrm{~m}^{3}$ and $[40.62$, $45.85] \times 10^{6} \mathrm{~m}^{3}$, respectively; in comparison, water supply design budget would be $[95.31,103.99] \times 10^{6} \mathrm{~m}^{3}$. Waste-water treatment limit budgets would be $[69.24,78.07] \times 10^{6} \mathrm{~m}^{3}$ (for industry), $\$[41.72,44.28] \times 10^{6} \mathrm{~m}^{3}$ (for municipal), and [70. $03,78.62] \times 10^{6} \mathrm{~m}^{3}$ (for agriculture), respectively. Net benefits generated from scenario 5 would be $\$[3403.07,4084.16]$ $\times 10^{6}$ (for industry), $\$[1991.62,2361.41] \times 10^{6}$ (for municipal) and $\$[1538.73,1834.10] \times 10^{6}$ (for agriculture), respectively. The results indicate that water supply for city 1 is mainly used to guarantee water demand from industry, then supply to agriculture and municipality; water allocated to city 2 is mainly for agriculture, then to industry and municipality. Industry users in city 1 bring the highest benefit when water demand is satisfied; whereas municipal and industry users in city 2 correbspond to lower benefits. The decision maker would pay attention to the basic demand of the water users in each city when the budget is low; when the budget is abundant, the decision maker can obtain more earnings from each water user. Besides, the water supply to city $2([95.31,103.99] \times$ $\left.10^{6} \mathrm{~m}^{3}\right)$ is higher than that to city $1\left([86.13,96.51] \times 10^{6} \mathrm{~m}^{3}\right)$. 
This is because city 2 possesses the higher earnings, higher wastewater treatment efficiency, and lower water supply cost. The amount of wastewater treated for industrial use would be $[69.24,78.07] \times 10^{6} \mathrm{~m}^{3}$; for municipal use would be $[41.72$, $44.28] \times 10^{6} \mathrm{~m}^{3}$; for agriculture use would be [70.03, 78.62] $\times$ $10^{6} \mathrm{~m}^{3}$. The results obtained can help decision maker design proper wastewater treatment facilities in water purifying industry, municipality and agriculture. Similarly, the solutions of model (24) under scenario 1 (i.e. when $\omega_{1}=0.1$ and $\omega_{2}=0.9$ obtained optimum-path ratios ${ }^{*} r^{+}=0.272$ and $\left.{ }^{*} r^{-}=0.268\right)$ and scenario 9 (i.e. when $\omega_{1}=0.9$ and $\omega_{2}=0.1$ obtained optimum-path ratios ${ }^{*} r^{+}=0.139$ and ${ }^{*} r^{-}=0.138$ ) could be interpreted based on the results presented as in Tables 4 and 6 . The results indicate that different scenarios would lead to varied system benefits and budgets and, at the same time, higher benefits would lead to higher budgets for wastewater treatment and supply.

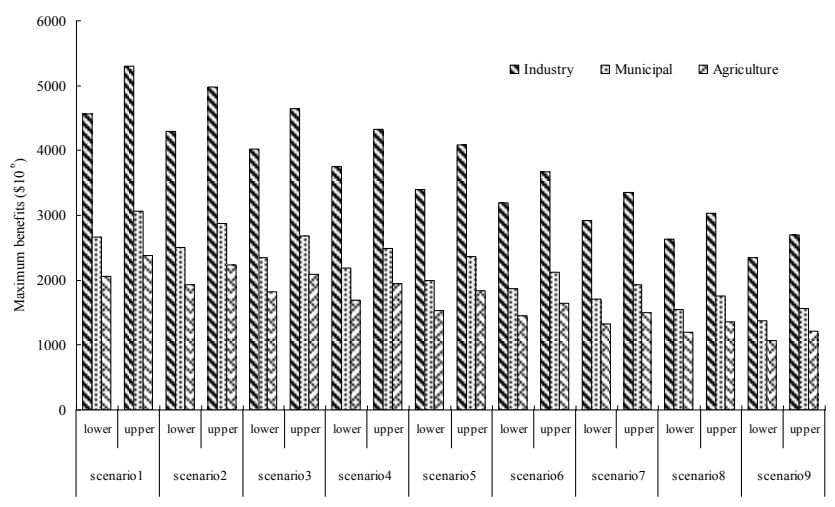

Figure 3. Maximum benefits at lower- and upper-bound under different scenarios.

The results indicate that different design budgets lead to varied water supply schemes as presented in Tables 4 to 6 . For example, for city 1 , water supplies would be $[115.41,125.0] \times$ $10^{6} \mathrm{~m}^{3}$ under scenario 1 and $[59.43,63.88] \times 10^{6} \mathrm{~m}^{3}$ under scenario 9; for city 2, water supplies would be $[127.72$, $134.69] \times 10^{6} \mathrm{~m}^{3}$ under scenario 1 and $[65.76,68.83] \times 10^{6} \mathrm{~m}^{3}$ under scenario 9. For industrial use, the amounts of wastewater treated would be $[92.78,101.11] \times 10^{6} \mathrm{~m}^{3}$ under scenario 1 and $[47.77,51.67] \times 10^{6} \mathrm{~m}^{3}$ under scenario 9; for municipal use, the amounts of wastewater would be [56.51, $56.75] \times 10^{6} \mathrm{~m}^{3}$ under scenario 1 and $[29.00,29.10] \times 10^{6} \mathrm{~m}^{3}$ under scenario 9, respectively; for agriculture use, the amounts of wastewater would be $[93.84,101.83] \times 10^{6} \mathrm{~m}^{3}$ under scenario 1 and $[48.32,52.04] \times 10^{6} \mathrm{~m}^{3}$ under scenario 9 , respectively. It is indicated that different optimum-path ratios (i.e. different $\omega$ ) would lead to different budgets; at the same time, different budgets would lead to different water supply quantities and treating wastewater amounts. For example, if scenario 1 is adopted, it means that budget corresponding to water supply and treating wastewater amount would be largest under an advantageous circumstance; but, it also has a highest risk of system-failure penalty when water shortage occurring. If scenario 9 is adopted, it means that budget corresponding to water supply and treating wastewater amount would be lowest under a disadvantageous circumstance; it may lead to a waste of resources. Generally, a higher budget would lead to higher water supply and treating wastewater amount, at the same time, a higher risk of system design failure when the water flow is low; in comparison, a lower budget would result in lower water supply and treating wastewater amount with a lower risk of penalty.

Figure 3 provides the net system benefits from industry, municipality and agriculture under different scenarios. Different optimum-path ratios correspond to different scenarios, and thus would lead to varied net system benefits. For example, system benefits for the industry would be $\$[4,560.12$, $5289.96] \times 10^{6}$ and $\$[2,348.12,2703.33] \times 10^{6}$ under scenarios 1 and 9, respectively; system benefits for the municipality would be $\$[2,668.77,3,058.59] \times 10^{6}$ and $\$[1,374.22$, $1,563.03] \times 10^{6}$ under scenarios 1 and 9 , respectively; system benefits for the agriculture would be $\$[2,061.89,2,375.59] \times$ $10^{6}$ and $\$[1,061.72,1,214.00] \times 10^{6}$ under scenarios 1 and 9 , respectively. The solutions under the other scenarios could be similarly interpreted based on the results presented in Figure 3. The results indicate that higher water allocation and wastewater treatment capacity correspond to higher system benefit, and lower water allocation and wastewater treatment capacity correspond to lower system benefit. Moreover, the benefit from the industry is higher than those from municipal and agricultural sectors. For instance, under the best-case scenario (i.e. scenario 1), the wastewater treatment capacity would be 92.78 $\times 10^{6}$ to $101.11 \times 10^{6} \mathrm{~m}^{3}$ for industry, $56.51 \times 10^{6}$ to $56.75 \times$ $10^{6} \mathrm{~m}^{3}$ for municipality and $93.84 \times 10^{6}$ to $101.83 \times 10^{6} \mathrm{~m}^{3}$ for agriculture (as shown in Table 4); it means that higher water allocation and higher water treatment efficiency and lower water supply cost could achieve higher benefits, but at the same time, a higher risk of penalty would generate when the promised water is not delivered under demanding conditions. Under the worst-case scenario (i.e. scenario 9), the wastewater treatment capacity would be $47.77 \times 10^{6} \mathrm{~m}^{3}$ to 51.67 $\times 10^{6} \mathrm{~m}^{3}$ for industry, $29.00 \times 10^{6} \mathrm{~m}^{3}$ to $29.10 \times 10^{6} \mathrm{~m}^{3}$ for municipality and $48.32 \times 10^{6} \mathrm{~m}^{3}$ to $52.04 \times 10^{6} \mathrm{~m}^{3}$ for agriculture (as shown in Table 6). The results indicate that lower water allocation and lower wastewater treatment efficiency and high water supply cost could bring about lower system benefit, less shortage, and lower penalty but, at the same time, more extra cost for wastewater treatment would be needed when future water flow level is high.

Through solving model (24), different $\lambda_{\text {meta }}$ levels can be obtained. Here, $\lambda_{\text {meta }}$ can be defined as meta-satisfaction degree corresponding to $\lambda$, and $\lambda_{\text {meta }}^{ \pm}={ }^{*} r \cdot \lambda_{\text {opt }}^{ \pm}$. The solutions of meta-satisfaction degree are presented in Figure 4. For example, the solution of $\lambda_{\text {meta }}^{ \pm}$would be $[0.20,0.27]$ under scenario 1 , which is the highest meta-satisfaction degree. This is because the raised strictness and the admissible violation of the uncertain flows under advantageous conditions. It is indicated that a plan with higher allocated flows is generated, resulting a higher system benefit and but, at the same time, a potentially higher penalty when the promised water is not delivered under demanding conditions (e.g., when the water flow level is low or low-medium). In comparison, under scenario 9 , the result 


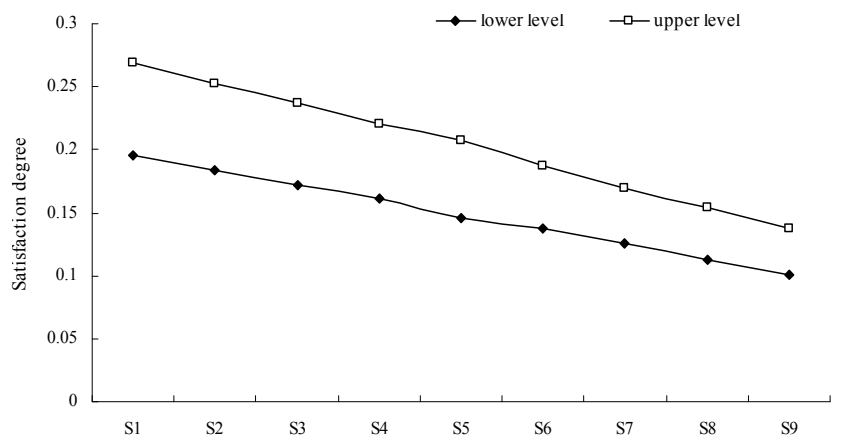

Figure 4. Meta-satisfaction degree under different scenarios (Symbol "S" denotes "scenario").

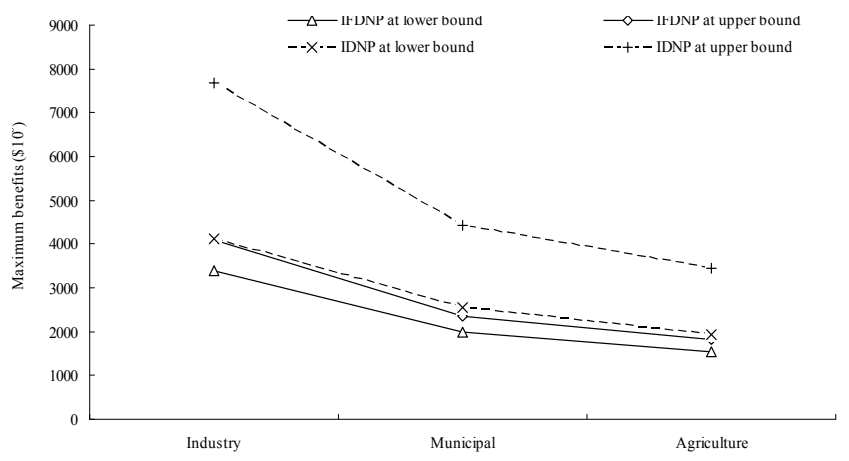

Figure 5. Maximum benefits from IFDNP and IDNP models.

of $\lambda_{\text {meta }}^{ \pm}$would be $[0.10,0.14]$; the meta-satisfaction degree would be lower than those under the other scenarios. This is because the admissible violations of the uncertain flows under demanding conditions. It is indicated that there would be lower benefit and thus lower system penalty but, at the same time, potentially more waste of resources when the water flow level is medium-high or high. Under scenario 5, the result of $\lambda_{\text {meta }}^{ \pm}$would be $[0.15,0.21]$; the solution would correspond to a situation when water availability stands between conservative and optimistic scenarios. The relaxations of system constraints would imply raised constraint-violation risks. Tightened resources availability limitations would then be associated with lower constraint-violation risks. Decisions with lower constraint-violation risks would be associated with a lower system benefit but increasing system reliability; a desire for higher benefit could result in raised risks of violating the system constraints. Therefore, different scenarios corresponding to different water supplies are associated with different options in handling the tradeoffs among system benefit, metasatisfaction degree, and constraint-violation risk.

\subsection{Comparison with IDNP}

The problem can also be solved through the inexact De Novo programming (IDNP) method by expressing uncertainties in the model's left and right hand sides as intervals (Zhang et al., 2009). Compared with IDNP (Zhang et al., 2009), IFDNP provides more information regarding tradeoffs among system benefits, certainty and reliability. Prior to further discussion, the uncertainty degree (UD) of an interval number $\left(x^{ \pm}\right)$can be defined as follows (Huang and Moore, 1993):

$U D\left(x^{ \pm}\right)=\frac{x^{+}-x^{-}}{\left(x^{+}+x^{-}\right) / 2} \times 100 \%$

where $x^{+}$is the upper bound of $x^{ \pm} ; x^{-}$is the lower bound of $x^{ \pm}$. This definition of an interval number can be understood as the ratio of its width to its difference. It demonstrates that when system is highly uncertain, UD becomes close to $100 \%$; when system turns out to be more deterministic, UD goes toward $0 \%$. Therefore, the concept of UD is useful for quantitatively evaluating the levels of uncertainties or the input/output data qualities for mathematical models (Qin et al., 2007).

Figure 5 presents a comparison of the system benefits obtained through IDNP and IFDNP models (take scenario 5 for example). The solutions of the system benefits from INDP model are intervals (i.e. $\$[4,121.4,7,682.1]$ million for industry, $\$[2,558.2,4,441.7]$ million for municipality, $\$[1,927.2$, $3,449.8$ ] million for agriculture), with corresponding UD of $60.34,53.82$ and $56.64 \%$, respectively. In comparison, the results from the IFDNP model would be $\$[3403$. 07, 4048.16] million for industry, $\$[1,991.62,2,361.41]$ million for municipality, $\$[1,538.73,1,834.10]$ million for agriculture, with a much lower UD (18.20, 17 and 17.52\%) than that from IDNP model. Because of the system benefits under other scenarios have similar tendency to Figure 5, the solutions under the other scenarios could be similarly interpreted. The UD of other scenarios through IFDNP are 14.82 (industry), 13.62 (municipality), and $14.14 \%$ (agriculture) under scenario 1, and 14.06 (industry), 12.86 (municipality), and 13.38\% (agriculture) under scenario 9, respectively. The resulting intervals from the IDNP model are much larger than those from the IFDNP model, and have larger width than those of the IFDNP model. It implies that solutions from the IDNP model are much more uncertain than those from IFDNP model.

Generally, the above results demonstrate that incorporating fuzzy items into IDNP can effectively reduce the uncertain degree of solutions. The main limitation of the IDNP is its over-simplification of fuzzy information into intervals. It is difficult to select the final or "best" decision alternatives from a number of solution options, especially for the problems of designing a new optimal system where the budget is unknown. This leads to the lack of system reliability information as defined by $\lambda_{\text {opt }}^{ \pm}$in the obtained solutions. The IFDNP approach has advantages over IDNP approach. The increased system certainty (i.e. the shrunk interval width) is based on a reduced certainty on the possibility of satisfying the constraints and aspiration. The IFDNP approach provides more information regarding trade offs among system benefits, certainty and reliability. As the actual value of each variable or parameter varies within its two bounds, the system benefit may change correspondingly between $z_{o p t}^{-}$and $z_{o p t}^{+}$with a variety of reliability levels.

The quality of information available for system modeling is often not good enough to be presented as either determine- 
stic numbers or probability distributions. Instead, some uncertainties can only be quantified as intervals or vague values. The IFDNP can handle uncertainties described as fuzzy sets and discrete intervals and offer flexibility in result interpretation and decision-alternative generation. Outputs of the IFDNP model can reflect fluctuations in system benefit (or budget) due to implementing different water-management policies; moreover, the IFDNP solutions contain information of system failure risk under varying water-management conditions. Thus, in practical implementations, fuzzy programming approaches are more applicable when the right-hand sides of the model constraints have large intervals.

\section{Conclusions}

An interval-fuzzy De Novo programming (IFDNP) method has been developed for planning water resources systems under uncertainty. The IFDNP improves upon the existing De Novo programming methods by allowing uncertainties presented as discrete intervals and fuzzy sets to be effectively incorporated within its optimization framework. In its solution process, the IFDNP can be transformed into two deterministic submodels that correspond to the lower and upper bounds of the objective function value. This transformation process is based on an interactive algorithm. For each submodel, the design variables in the IFDNP model are constrained by the total budget. By function transformation, the maximum value of each objective function can be obtained, corresponding to the performance of the ideal design under a given B. A metaoptimum model can be constructed and solved to get optimal design solutions for all scenarios.

The developed IFDNP approach is useful for designing an optimal system rather than optimizing a given system. It can effectively deal with the system design problems involving multiple objectives and multiple uncertainties. In the conventional multiobjective programming problems, trade-offs exist among multiple objectives, particularly for conflicting ones. Scenarios are often analyzed and a set of decision results are generated for reflecting the tradeoffs. In the water resources allocation problem, decision makers are confronted with control and adjustment of water disposal facility design and operation characterristics. IFDNP is such an integrated approach for planning, provision, and management of urban water resources systems. It can eliminate the tradeoffs through designing a better and preferably optimal system. Based on the IFDNP, the minimum water allocation to each city can be determined, which means a tight system in terms of resources identification; at the same time, a higher objective function value can be obtained. Moreover, the IFDNP can generate results under all possible scenarios preferred by the decision makers, including design decision variables and management decision variables, and the obtained results can provide effecttive decision support for the decision makers to design an optimal system. Within multiobjective decision making framework, IFDNP may allow the decision makers to achieve a metaoptimal system performance and improve the performance of compromise solutions.
Generally, the IFDNP has advantages in constructing optimal system design via an ideal system by introducing the flexibility toward the available resources in the system constraints. However, there are some improvements for the IFDNP. In IFDNP, decision makers need to analyze many scenarios and determine the aspiration and/or preference levels, tolerances of the objective functions and/or the constraints, and weight for multiple objectives. These are based on the decision makers' subjectivity or for the simplicity. Although this study is the first attempt for planning water resources systems through the developed IFDNP approach, the obtained results suggest that it can be extended to other practical problems involving optimal environmental systems design under uncertainty.

Acknowledgments. This research was supported by the National Basic Research Program (2013CB430401), the National Natural Sciences Foundation of China (51225904 and 51190095), the 111 Project (B14008) and the Program for Innovative Research Team in University (IRT1127). The authors are extremely grateful to the editor and the reviewers for their comments and suggestions.

\section{References}

Barbalios, N., Ioannidou, I., Tzionas, P., Paraskeuopoulos, S. (2013). Behavioural adaptation towards efficient resources haring under the lack of communication. J. Environ. Inf., 21(2), 119-135. http:// dx.doi.org/10.3808/jei.201300239

Bare, B.B., and Mendoza, G.A. (1988). A soft optimization approach to forest land management planning. Can. J. For. Res., 18(5), 545-552. http://dx.doi.org/10.1139/x88-079

Bare, B.B., and Mendoza, G.A. (1990). Designing forest plans with conflicting objectives using de Novo programming. J. Environ. Manage., 31(3), 237-246. http://dx.doi.org/10.1016/S0301-4797(0 5) $80037-4$

Bender, M.J., and Simonovic, S.P. (2000). A fuzzy compromise approach to water resources planning under uncertainty. Fuzzy Sets Syst., 115(1), 35-44. http://dx.doi.org/10.1016/S0165-0114(99)000 25-1

Chang, N.B., Wen, C.G., Chen, Y.L., and Yong, Y.C. (1996). A grey fuzzy multiobjective programming approach for the optimal planning of a reservoir watershed. Part A. Theoretical development. Water Res., 30(10), 2329-2334. http://dx.doi.org/10.1016/0043-13 54 (96)00124-8

Chang, N.B., Chen, Y.L., and Wang, S.F. (1997). A fuzzy interval multiobjective mixed integer programming approach for the optimal planning of solid waste management systems. Fuzzy Sets Syst., 89(1), 35-60. http://dx.doi.org/10.1016/S0165-0114 (96)00086-3

Chen, Y.W., and Hsieh, H.E. (2006). Fuzzy multi-stage de Novo programming problem. Appl. Math. Comput., 181(2), 1139-1147. http://dx.doi.org/10.1016/j.amc.2006.01.083

Dubois, D., and Prade, H. (1978). Operations on fuzzy number. Int. J. Syst. Sci., 9(6), 613-626. http://dx.doi.org/10.1080/00207727808 941724

Fan, Y.R., Huang, G.H. (2012). A robust two-step method for solving interval linear programming problems within an environmental management context. J. Environ. Inf. 19(1):1-12. http:// dx.doi.org/

Ferrero, R.W., Rivera, J.F., and Shahidehpour, S.M. (1998). A dynamic programming two-stage algorithm for long-term hydro-thermal scheduling of multireservoir systems. IEEE Trans. Power Syst., 13(4), 1534-1540. http://dx.doi.org/10. 1109/59.736302

Huang, G.H., Baetz, B.W., and Patry, G.G. (1993). A grey fuzzy linear 
programming approach for municipal solid waste management planning under uncertainty. Civ. Eng. Environ. Syst., 10(2), 123146. http://dx.doi.org/10.1080/026302593089 70119

Huang, G.H. (1996). IPWM: an interval parameter water quality management model. Eng. Optimiz., 26(2), 79-103. http://dx.doi.org/ $10.1080 / 03052159608941111$

Huang, G.H., Sae-Lim, N., Liu, L., and Chen, Z. (2001). An intervalparameter fuzzy stochastic programming approach for municipal solid waste management and planning. Environ. Model. Assess. 6(4), 271-283. http://dx.doi.org/10.1023/A:10 13394118863

Huang, G.H., Sun, W., Nie, X.H., Qin, X.S., and Zhang, X.D. (2010). Development of a decision support system for rural eco-environmental management in Yongxin county, Jiangxi province, China. Environ. Model. Software, 25(1), 25-42. http://dx.doi.org/ 10.1016/j.envsoft.2009.07.010

Huang, W.C., Liaw, S.L., and Chang, S.Y. (2010). Development of a systematic object-event data model of the database system for industrial wastewater treatment plant management. J. Environ. Inf., 15(1), 14-25. http://dx.doi.org/10.3808/ jei.201000162

Jairaj, P.G., and Vedula, S. (2000). Multireservoir system optimazation using fuzzy mathematical programming. Water Res. Manag., 14(6), 457-472. http://dx.doi.org/10.1023/A:1011117 918943

Kindler, J. (1992). Rationalizing water requirements with aid of fuzzy allocation model. ASCE J. Water Res. Plann. Manage., 118(3), 308-318. http://dx.doi.org/10.1061/(ASCE)0733-9496 (1992)118:3 (308)

Kim, H., Ida, K., and Gen, M. (1993). A de Novo approach for bicriteria 0 -1 linear programming with interval coefficients under gub structure. Comput. Ind. Eng., 25(1-4), 17-20. http://dx.doi.org/ 10 1016/0360-8352(93)90210-O

Kotula, A.S. (1997). Toward sustainable reservoir design: Application of de Novo programming, Thesis (Master of Science), University of Manitoba, Winnipeg, CA.

Lee, C.S., and Chang, S.P. (2005). Interactive fuzzy optimization for an economic and environmental balance in a river system. Water Res., 39(1), 221-231. http://dx.doi.org/10.1016/j.watres.2004.09.0 13

Li, R.J., and Lee, E.S. (1990). Multicriteria de Novo programming with fuzzy parameters. Comput. Math. Appl., 19(5), 13-20. http:// dx.doi.org/10.1016/0898-1221(90)90097-4

Li, R.J., and Lee, E.S. (1993). De Novo programming with fuzzy coefficients and multiple fuzzy goals. J. Math. Anal. Appl., 172(1), 212-220. http://dx.doi.org/10.1006/jmaa.1993.1018

Li, Y.P., Huang, G.H., Yang, Z.F., and Nie, S.L. (2008a). Interval-fuzzy multistage programming for water resources management under uncertainty. Res., Conserv. Recycling, 52(5), 800-812. http://dx. doi.org/10.1016/j.resconrec.2007.11. 007

Li, Y.P., Huang, G.H., Nie, S.L., and Mo, D.W. (2008b). Intervalparameter robust quadratic programming for water quality management under uncertainty. Eng. Optimiz., 40(7), 613-635. http://dx. doi.org/10.1080/03052150801918347

Li, Y.P., Huang, G.H., Huang, Y.F., and Zhou, H.D. (2009). A multistage fuzzy-stochastic programming model for supporting sustainable water-resources allocation and management. Environ. Mode. Software, 24(7), 786-797. http://dx.doi.org/10.1016/j.envso ft.2008.11.008

Li, Y. P., Huang, G. H., and Sun, W. (2011). Management of uncertain information for environmental systems using a multistage fuzzystochastic programming model with soft constraints. J. Environ. Inf., 18(1), 28-37. http://dx.doi.org/10. 3808/jei.201100196

Maqsood, I., Huang, G.H., and Yeomans, J.S. (2005). An intervalparameter fuzzy two-stage stochastic program for water resources management under uncertainty. Eur. J. Oper. Res., 167(1), 208-225. http://dx.doi.org/10.1016/j.ejor.2003.08. 068
Qin, X.S., Huang, G.H., Zeng, G.M., Chakma, A., and Huang, Y.F. (2007). An interval-parameter fuzzy nonlinear optimazation model for stream water quality management under uncertainty. Eur. J. Oper. Res., 180(3), 1331-1357. http://dx. doi.org/10.1016/j.ejor.20 06.03 .053

Russell, S.O., and Campbell, P.F. (1996). Reservoir operating rules with fuzzy programming. ASCE J. Water Res. Plann. Manage., 122(3), 165-170. http://dx.doi.org/10.1061/(ASCE) 0733-9496 (19 96)122:3(165)

Sasaki, M., Gen, M., and Yamashiro, M. (1995). A method for solving fuzzy de Novo programming problem by genetic algorithms. Comput. Ind. Eng., 29(1-4), 507-511. http://dx.doi.org/10.1016/03 60-8352(95)00125-K

Seifi, A., and Hipel, K.W. (2001). Interior-point method for reservoir operation with stochastic inflows. SCE J. Water Res. Plann. Manage., 127(1), 48-57. http://dx.doi.org/10.1061/(ASCE)0733-9496(20 01)127:1(48)

Shi, Y. (1995). Studies on optimum-path ratios in multicriteria de Novo programming-problems. Comput. Math. Appl., 29(5), 43-50. http://dx.doi.org/10.1016/0898-1221(94)00247-I

Slowinski, R. (1986). A multicriteria fuzzy linear programming method for water supply system development planning. Fuzzy Sets Syst., 19(3), 217-237. http://dx.doi.org/10.1016/0165-0114(86)90052-7

$\mathrm{Su}$, L.Y., Christensen, P., Liu, J.L. (2013). Comparative study of water resource management and policies for ecosystems in China and Denmark. J. Environ. Inf. 21(1), 72-83. http://dx.doi.org/10.3808/ jei.201300234

Su, M.R., Yang, Z.F., Liu, G.Y., and Chen, B. (2011). Ecosystem health assessment and regulation for urban ecosystems: A case study of the Yangtze River delta urban cluster, China. J. Environ. Inf., 18(2), 65-74. http://dx.doi.org/10.3808/jei.2011 00200

Suo, M.Q., Li, Y.P., Huang, G.H., Deng, T.L., Li, Y.F. (2013). Electric power system planning under uncertainty using inexact inventory nonlinear programming method. J. Environ. Inf. 22(1), 49-67. http: //dx.doi.org/10.3808/jei.201300245

Teegavarapu, R.S.V., and Simonovic, S.P. (1999). Modeling uncertainty in reservoir loss functions using fuzzy sets. Water Resour. Res., 3(9), 2815-2823. http://dx.doi.org/10.1029/1999 WR900165

Wu, S.M., Huang, G.H., and Guo, H.C. (1997). An interactive inexact-fuzzy approach for multiobjective planning of water resource systems. Water Sci. Technol., 36(5), 235-242. http:// dx. doi.org/10. 1016/S0273-1223(97)00479-4

Xu, T.Y., Qin, X.S. (2013). Solving water quality management problem through combined genetic algorithm and fuzzy simulation. $J$. Environ. Inf. 22(1):39-48. http://dx.doi.org/10.3808/jei.201300244

Zeleny, M. (1981). A case study in multiobjective design: De Novo programming, in: Nijkamp, P., Spronk, J. (Eds.), Multiple Criteria Analysis: Operational methods, Gower publishing company, Hampshire, England.

Zeleny, M. (1986). Optimal system design with multiple Criteria: De Novo programming approach. Eng. Costs Prod. Econ., 10(2), 89-94. http://dx.doi.org/10.1016/0167-188X(86) 90002- 9

Zeleny, M. (1990). Optimizing given systems vs. designing optimal systems: The de Novo programming approach. International $J$. Gen. Syst., 17(4), 295-307. http://dx.doi.org/10.1080/0308107900 8935113

Zeleny, M. (2005). The evolution of optimality: De Novo programming, in: Coello, C. A. et al., (Eds.), Evolutionary Multi-Criterion Optimization, Springer-Verlag, Heidelberg Berlin, pp. 1-13.

Zhang, Y.M., Huang, G.H., and Zhang, X.D. (2009). Inexact de Novo programming for water resources systems planning. Eur. J. Oper. Res., 199(2), 531-541. http://dx.doi.org/10.1016/j.ejor.2008.11.019

Zimmermann, H.-J. (1995). Fuzzy Set Theory and its Applications, 3rd ed, Kluwer Academic Publishers, Dordrecht Massachusetts 